\title{
ESTRUTURA E CONSCIÊNCIA DE CLASSE OPERÁRIA NO BRASIL
}

\author{
Michael Löwy*
}

\begin{abstract}
Originalmente publicado em francês, no Cahier Internatinaux de Sociologie, em 1970, este artigo foi traduzido especialmente para este Dossiê, com o objetivo apresentar para as novas gerações as reflexões e a pesquisa, no campo da sociologia do trabalho, de um jovem estudante da USP que, posteriormente, se tornaria um dos mais importantes autores das ciências sociais brasileiras. Nesse sentido, o texto tem um valor histórico inigualável, sem perder a atualidade de sua problemática. O objetivo do artigo é elucidar alguns problemas relativos à estrutura da consciência de classe de um grupo de trabalhadores presente num congresso sindical de 1959. A referência teórica para esta empreita é o marxismo, perspectiva que, na época da pesquisa, estava alheia ao meio acadêmico.

Palavras-chave: Consciência operária. Consciência de classe. Identidade de classe. Sindicalismo brasileiro. Marxismo.
\end{abstract}

\section{INTRODUÇÃO}

Este artigo ${ }^{1}$ busca analisar alguns aspectos da "consciência de classe" em um grupo de 82 dirigentes sindicais, delegados do II Congresso Nacional de Trabalhadores Metalúrgicos, que ocorreu no município de Itanhaém, próximo de São Paulo, em abril de 1959. Os delegados, eleitos nas assembleias gerais dos sindicatos, na proporção de um para cada cinco mil operários, provinham de diversos Estados da Federação brasileira: São Paulo (a delegação mais importante), Rio de Janeiro, Guanabara, Rio Grande do Sul, Minas Gerais, Santa Catarina, Paraná, Pará, Ceará e Alagoas.

No sistema industrial do Brasil, a metalurgia se apresenta como um dos setores mais

\footnotetext{
* École des Hautes Études en Sciences Sociales. Centre d'Études en Sciences Sociales du Religieux - CéSor.

10 rue Monsieur le Prince 75006. Paris. michael.lowy1@ gmail.com

1 Tradução realizada por Ricardo C. Festi de Löwy, M. "Structure de la conscience de classe ouvrière au Brésil" In: Cahier Internationaux de Sociologie, n. 49, p. 133-142, jul. 1970. Para uma compreensão do contexto intelectual em que este artigo foi produzido, recomendamos a leitura do artigo "Michael Löwy e a sociologia do trabalho", publicado neste Dossiê.
}

modernos, em rápida expansão; no Estado de São Paulo, os operários metalúrgicos já constituíam a seção mais importante $(28,37 \%)$ da massa operária da indústria, assim como um dos setores mais ativos, como revelam trabalhos recentes: mais de $90 \%$ das fábricas metalúrgicas estiveram em greve ao longo do período de 1955 a 1961 (Cf. Rodrigues, 1966, p. 83).

\section{ESTRUTURA DA CONSCIÊNCIA DE CLASSE}

A escola marxista de ciências sociais formulou a teoria sociológica "clássica" da consciência de classe. Uma primeira tentativa de distinção conceitual entre os diferentes níveis estruturais da consciência de classe do proletariado já se manifestava nos escritos de Karl Marx. Em uma de suas primeiras obras, $A$ Sagrada Família (1945), ele distinguiu entre as concepções ocasionais que o proletariado tem sobre sua situação e a "autentica consciência de classe" ou "consciência da missão histórica da classe operária” (Marx, 1953, p. 138).

Essa passagem de A Sagrada Família 
inspirou a teoria da consciência de classe de Lukács (também influenciada por Max Weber), que diferenciou a "consciência psicológica dos proletários”, cujo conteúdo pode variar e que é, geralmente, orientada por interesses econômicos imediatos, da "consciência de classe do proletariado", um tipo ideal definido como "o sentido, que se tornou consciente, da situação histórica da classe”, atitude racional e adequada, que pode ser logicamente atribuída à classe (Lukács, 1959, p. 99).

A obra de Lenin Que fazer? (1902) propôs uma aproximação análoga, porém mais precisa. O autor estabeleceu uma distinção fundamental entre dois níveis de consciência de classe do proletariado: "a consciência sindical”, definida como a "convicção de que é necessário se organizar em sindicatos, lutar contra a patronal, reivindicar ao governo tais e tais leis necessárias aos operários, etc.”, e a "consciência socialdemocrata”, ou seja, "a consciência da oposição irredutível entre os interesses dos operários e a ordem política e social atual" (Lênin, 1966, p. 85).

Nas ciências sociais contemporâneas, somente um pequeno número de psicólogos sociais e de sociólogos analisou o problema dos níveis estruturais da consciência de classe proletária. Entre os primeiros, a obra mais sig$\stackrel{\infty}{a}$ nificativa é a de Richard Centers, que distinguiu dois elementos da consciência de classe: (a) o sentimento de pertencimento a uma classe; e (b) certas ideias e atitudes-tipo. Para medir essa segunda dimensão, Centers construiu um conjunto de perguntas que opunham radicalismo e conservadorismo, centrado, essencialmente, em dois aspectos cruciais: a atitude a face aos conflitos de classe (greves, relações के entre empregado e empregador) e as ideologias sociopolíticas (individualismo e coletivismo, propriedade privada e propriedade pública, poder da classe operária, etc.) (Cf. Centers, 1949). Entre os sociólogos, convém mencionar Alain Touraine, que, em sua recente obra, $L a$ conscience Ouvrière (1966), distinguiu entre a "consciência operária”, descrita como "o senti- do, para o trabalhador, de certo estado de relação entre o homem e suas obras", e a "consciência de classe”, forma específica da consciência operária produzida pela reunião particular de três "princípios" básicos:

\begin{abstract}
o princípio de identidade ou consciência de pertencer a um grupo, de ser membro de uma classe;

o princípio de oposição ou consciência de antagonismo e de hostilidade frente aos empregadores-exploradores;

o princípio de totalidade, ou seja, o antagonismo de classe projetado como princípio central de funcionamento da sociedade; a oposição à ordem social estabelecida; um modelo voluntário de sociedade diferente; a consciência de uma 'missão histórica' (Touraine, 1966, p. 16,17, 124, 328-332).
\end{abstract}

Este estudo tenta aplicar os instrumentos conceituais definidos acima (Marx, Lenin, Lukács, etc.) a um setor determinado da direção dos sindicatos brasileiros, o da metalurgia, colocando em evidencia três níveis estruturais de consciência de classe: a consciência da identidade de classe, a consciência sindical e a consciência de classe fundada sobre uma ideologia radical, que chamaremos consciência radical-ideológica.

\section{Consciência de identidade de classe}

Por consciência de identidade de classe entende-se a consciência de pertencimento à classe operária, o que jamais pode ser considerado como algo dado. As pesquisas de Richard Centers mostraram que 20\% dos operários americanos se consideravam como pertencentes à classe média (Centers, 1949, p. 86), e, na Inglaterra, 25\% dos operários da indústria pesada, das ferrovias e das minas, tinham a mesma atitude (Dogan, 1960).

Não dispomos, para o Brasil, de dados precisos sobre esse problema, e nosso estudo não nos forneceu nenhuma informação direta sobre a consciência "da identidade de classe" entre operários brasileiros. Mas, para a análise dos dois outros níveis de consciência de classe, foi necessário levar em conta, implicitamente, 
a existência prévia desse "primeiro grau" e, dessa forma, estudar os fatores que permitem a passagem desse nível aos de consciência sindical e de consciência radical-ideológica.

\section{Consciência sindical}

A consciência sindical implica uma certa apreensão do antagonismo com os empregadores e uma concepção de sindicato como instrumento de reivindicação operária nessa relação. No Brasil, a filiação a um sindicato não leva automaticamente à "consciência sindical”. Para muitos dos operários sindicalizados, o sindicato não se apresenta prioritariamente como um órgão coletivo de luta e de defesa dos interesses socioeconômicos comuns, mas como uma espécie de escritório governamental que oferece gratuitamente serviços médicos, legais, etc. (Simão, 1960). O sociólogo brasileiro Juarez R. B. Lopes, num estudo sobre os operários de uma importante indústria de São Paulo, sugeriu que eles consideravam o sindicato como uma instituição de ajuda mútua, semelhante ao Instituto de Aposentadorias e Pensões dos Industriários (IAPI) ${ }^{2}$ - o serviço oficial de assistências sociais -, ou mesmo ao Serviço Social da Indústria (SESI) - gerido pela autoridade patronal. Como exemplo típico dessa concepção, compartilhada por uma grande parte de operários sindicalizados, Lopes cita um entusiasmado sindicalista:

O sindicato é a melhor coisa que nós temos. Nós aportamos menos para o sindicato que para o IAPI e o SESI, que nos socorrem somente em casos de doença grave. No interior do sindicato, nós possuímos todos os direitos: direito ao médico, direito ao farmacêutico, direito ao advogado, sem nenhum custo (Lopes, 1957, p. 318-319).

É necessário, portanto, determinar quantos de nossos líderes sindicais demons-

${ }^{2}$ O IAPI foi criado em 1936 e, após 1945, expandiu as suas áreas de atuação, passando a financiar, dentre outros, projetos de habitação popular. Em 1966, o IAPI foi fundido com outras instituições de aposentadoria e deu origem ao Instituto Nacional de Previdência Social (INPS) (N.T.). tram uma verdadeira consciência sindical no sentido leninista do termo, ou seja, entendem o sindicato como uma organização de trabalhadores em luta contra os empregadores com o objetivo de adquirir e defender seus direitos.

\section{Consciência radical-ideológica}

Designaremos por consciência radical-ideológica o que Lenin chamava de "consciência socialdemocrata", Centers de "atitude radical" e Touraine de "princípio da totalidade", ou seja, concretamente, o nível de consciência de classe desses operários brasileiros que, sustentando uma ideologia sociopolítica "radical" (comunismo, socialismo ou anarquismo), manifestam certo grau de oposição à ordem social existente.

No Brasil, o caráter precário dessa consciência "radical", suas contradições internas, suas inconsistências e suas fraquezas não a impedem de constituir um nível qualitativamente diferente da "consciência sindical" (que não coloca em questão o regime socioeconômico).

\section{A CONSCIÊNCIA SINDICAL}

A pergunta de nosso questionário, que visava a determinar as concepções de sindicato dos delegados do Congresso dos Metalúrgicos, foi assim formulada:

Em sua opinião, qual é o objetivo essencial do sindicato?

I. Unir e organizar os trabalhadores na luta pela obtenção de suas reivindicações.

II. Fornecer aos trabalhadores cuidados médicos, odontológicos e assistência legal.

III. Se for o caso, especificar os outros objetivos:

As respostas se repartiram em dois grupos-tipos: um grupo escolheu o primeiro termo ( $I$ ) de alternativas, e o outro assinalou o primeiro e o segundo ( $I$ e $I I$ ). Ninguém optou somente pela proposição II. A resposta aberta 
(III, “outros objetivos”) não foi assinalada sozinha, mas sempre em complemento a outras escolhas. Encontramos, por exemplo, nessa última resposta, formulações tais como: "defesa da indústria nacional”, "educação”, "explicação dos problemas", "cultura”, etc.

As porcentagens obtidas foram as seguintes.

\begin{tabular}{c|c}
\hline $\begin{array}{c}\text { Escolha de duas } \\
\text { proposições (I e II) }\end{array}$ & $\begin{array}{c}\text { Apenas "Unir } \\
\text { e organizar os } \\
\text { trabalhadores" (I) }\end{array}$ \\
\hline $25,6 \%$ & $74,4 \%$ \\
\hline
\end{tabular}

Segundo o nosso quadro conceitual, esse segundo grupo $(74,4 \%)$ compreende a consciência sindical. Por outro lado, aqueles que não consideram o sindicato, em primeiro lugar e antes de tudo, como um órgão de reagrupamento e de luta da classe operária, ainda estão, provavelmente, no nível da consciência da identidade de classe. Para eles, os serviços gratuitos do médico, do dentista e do advogado não constituem apenas os elementos complementares, mas essenciais e próprios aos sindicatos, tanto que tais elementos são, ao menos, tão importantes quanto as reivindicações salariais, as greves, a luta contra o custo elevado de vida, etc. Sua atitude reflete, até certo ponto, a de trabalhadores que veem o sindicato como um serviço público de ajuda mútua.

: vincular à formação da consciência sindical (grau de urbanização, idade, nível de instrução, escala salarial, qualificação profissional, యิ tempo na empresa), somente a escala salarial 岕 ofereceu a possibilidade real de estabelecer ¿. uma correlação:

$\infty$

\begin{tabular}{|c|c|c|}
\hline Escala salarial $^{3}$ & $\begin{array}{c}\text { Escolha de duas } \\
\text { proposições (I e II) }\end{array}$ & $\begin{array}{c}\text { Unir e } \\
\text { organizar } \\
\text { (I) }\end{array}$ \\
\hline $\begin{array}{l}\text { Menos de } 6.000 \\
\text { cruzeiros }\end{array}$ & $42,9 \%$ & $57,1 \%$ \\
\hline $\begin{array}{l}\text { De } 6.000 \text { a } 9.000 \\
\text { cruzeiros }\end{array}$ & $24,0 \%$ & $76,0 \%$ \\
\hline $\begin{array}{l}\text { Mais de } 9.000 \\
\text { cruzeiros }\end{array}$ & $10,7 \%$ & $89,3 \%$ \\
\hline
\end{tabular}

A relação positiva entre a participação sindical e os salários mais elevados é um fato reconhecido no seio dos sindicatos brasileiros. Frequentemente, durante seus eventos, os operários ou os dirigentes sindicalistas se queixam da ausência ou da apatia da camada social de menor remuneração, particularmente daqueles que recebem o salário mínimo e que jogam um rol muito ínfimo nas atividades sindicais. Esse paradoxo e a correlação revelada por nosso estudo entre os salários mais elevados e a consciência sindical tornam-se plausíveis se consideramos que, ao ganhar decentemente e estar liberado das dificuldades econômicas mais prementes, é mais provável que o trabalhador, a par da sua situação, pense mais em termos relativamente gerais e abstratos ("Unir e organizar os trabalhadores”) que o operário mais desfavorecido, interessado somente nas vantagens mais imediatas e "concretas" que o sindicato lhe pode proporcionar (médico, farmacêutico, serviços sociais, etc.).

Entre as outras opiniões examinadas no questionário, a atitude do governo em relação às classes sociais foi a que apresentou a melhor correlação com a consciência sindical. ${ }^{4} \mathrm{Na}$ questão relativa a esse tópico, os operários ou indicavam que o governo favorecia os patrões, ou se se posicionavam na resposta "imparcial", conforme demonstram os resultados a seguir apresentados.

\begin{tabular}{c|c|c}
\hline $\begin{array}{c}\text { Favorece os } \\
\text { trabalhadores }\end{array}$ & Imparcial & $\begin{array}{c}\text { Favorece os } \\
\text { patróes }\end{array}$ \\
\hline $2,4 \%$ & $30,5 \%$ & $67,1 \%$ \\
\hline
\end{tabular}

Entre as opiniões emitidas sobre a atitude do governo e as concepções quanto ao objetivo do sindicato, podemos estabelecer as porcentagens seguintes:

\footnotetext{
${ }^{4}$ Nessa época (1959), o governo era constituído por uma coalisão do Partido Social Democrata, um partido centrista moderado, mais ou menos ligado aos meios industriais e financeiros, ao qual pertencia o Presidente Juscelino Kubitschek, com o Partido Trabalhista Brasileiro, saído do partido trabalhista e dirigido pelo vice-presidente João Goulart. Os dois partidos foram fundados em 1945 pelo ex-ditador e líder popular carismático Getúlio Vargas.
} 


\begin{tabular}{c|c|c}
\hline Atitude do governo & $\begin{array}{c}\text { Escolha de duas } \\
\text { proposiçóes (I } \\
\text { e II) }\end{array}$ & $\begin{array}{c}\text { Unir e } \\
\text { organizar } \\
\text { (I) }\end{array}$ \\
\hline $\begin{array}{c}\text { Favorecer os } \\
\text { operários }\end{array}$ & $100 \%$ & $0,0 \%$ \\
\hline Imparcial & $40,0 \%$ & $60,0 \%$ \\
\hline $\begin{array}{c}\text { Favorecer os } \\
\text { patróes }\end{array}$ & $16,4 \%$ & $83,6 \%$ \\
\hline
\end{tabular}

A correlação não é falsa nem acidental. Ela reflete um dos problemas cruciais da estrutura sindical brasileira. Em 1937, o presidente Vargas criou os sindicatos "oficiais", reconhecidos e protegidos pelo Estado, com um caráter de órgão semigovernamental, no lugar dos antigos sindicatos que, até então, eram pequenas organizações de luta e de agitação contra o capitalismo e o Estado. Eles foram, portanto, colocados sob o controle estrito do Ministério do Trabalho. Após a queda de Vargas em 1945, organizou-se um lento processo de rejeição da dominação e da intervenção do governo, considerada como favorável ao patronato, e de ruptura da relação de paternalismo entre o Estado e os sindicatos. Esse processo permitiu a emergência da consciência sindical, mas, em 1959, ele estava longe de ter acabado. Importantes seções sindicais se encontravam ainda sob a influência e o controle direto do Ministério do Trabalho (dominado pelo Partido Trabalhista Brasileiro, o PTB) e uma grande parte da massa operária considerava ainda o sindicato como uma instituição de ajuda mútua quase oficial.

\section{A CONSCIÊNCIA RADICAL-IDEO- LÓGICA}

No Brasil, desde o início do século XX até 1959, duas grandes correntes "de ideologia radical" tiveram um rol importante no movimento sindical: os anarquistas, cuja influência foi preponderante até meados de 1930, e o Partido Comunista Brasileiro. Existiam também alguns grupos socialistas dispersos e ineficazes, aos quais alguns se uniram em 1945 para formar o Partido Socialista Brasileiro. A ideolo- gia do PTB (o partido trabalhista), uma mistura suis generis de nacionalismo, sindicalismo e "estado-provedor", não coloca em questão o regime social e econômico e não pode ser qualificada de "radical".

Tentamos determinar as fidelidades ideológicas dos dirigentes sindicais colocando a seguinte questão:

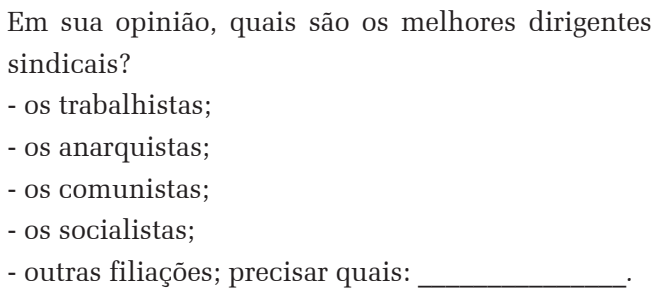

O último item recebeu uma enorme porcentagem de respostas, todas caracterizadas por uma recusa de alinhamento político. Vejamos alguns exemplos: "Todos os partidos contam com bons e maus dirigentes"; "Eu não jugo os dirigentes sindicais pelas cores de um partido político"; "Os melhores dirigentes sindicais são aqueles que defendem ativamente os operários de sua profissão"; "Aqueles que não misturam política e sindicato"; "Aqueles que anunciam sua ideologia política”; etc. Alguns operários simplesmente se recusaram a responder a essa questão: "Tais questões são inúteis"; "Eu considero esta questão deslocada”, etc.

Se agrupamos todas essas respostas sob a etiqueta "Sindicalizados sem filiação política”, obtemos a seguinte distribuição:

\begin{tabular}{c|c|c}
\hline $\begin{array}{c}\text { Comunistas e } \\
\text { socialistas }\end{array}$ & $\begin{array}{c}\text { Sem filiação } \\
\text { política }\end{array}$ & Trabalhistas $^{5}$ \\
\hline $32,9 \%$ & $25,6 \%$ & $41,5 \%$ \\
\hline
\end{tabular}

Se considerarmos o grupo socialista-comunista como aquele que melhor corresponde ao tipo de consciência radical-ideológica, notamos uma acentuada correlação entre a ideologia e o grau de urbanização. Para isso, os dele-

${ }^{5}$ Nenhum delegado se filiava às ideias anarquistas; nos sindicatos mais antigos, de origem semiartesanal, como os tipógrafos e os sapateiros, ainda existem pequenos grupos de militantes anarquistas. 
gados foram repartidos, segundo seus lugares de origem, em duas seções caracterizadas pelo grau de urbanização:

Zone 1: São Paulo e seus arredores, Rio de Janeiro (Estado da Guanabara).

Zona 2: Todos as outras cidades do país representada no Congresso.

A relação entre zona e ideologia é impressionante:

\begin{tabular}{l|c|c|c}
\hline Zonas & $\begin{array}{c}\text { Comunistas } \\
\mathbf{e} \\
\text { Socialistas }\end{array}$ & $\begin{array}{c}\text { Sem } \\
\text { filiação } \\
\text { política }\end{array}$ & Trabalhistas \\
\hline Zona 1 & $66,5 \%$ & $29,3 \%$ & $4,2 \%$ \\
\hline Zona 2 & $18,9 \%$ & $24,1 \%$ & $57,0 \%$ \\
\hline
\end{tabular}

Azis Simão, professor da Universidade de São Paulo, em um de seus estudos sobre o voto operário em São Paulo, obteve resultados similares: durante o período de 1947 a 1950, existia, entre os trabalhadores urbanos de origem rural, uma tendência a votar no PTB; já entre aqueles nascidos em São Paulo, uma proporção maior escolhia votar nos candidatos do Partido Comunista (Cf. Simão, 1955).

Parece plausível que o processo de urbanização, o meio sociocultural das grandes cidades, a racionalização e a secularização das relações sociais, a ruptura dos laços tradicionais e familiares e sua substituição por uma relação de classe impessoal, bem como a

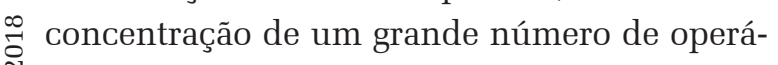
: rios em grandes empresas criam as condições favoráveis à emergência e à cristalização dos elementos constitutivos da consciência radical-ideológica.

Entre esses elementos, um dos mais essenciais é, talvez, a tomada de consciência da luta de classes como antagonismo conflitual.

$\dot{a}$ Portanto, inserimos, em nosso questionário, a seguinte questão:

: Em sua opinião, o conflito entre operários e patrões tem origem:

- da oposição de interesses entre operários e patrões;

- de um mal-entendido;

- de outras razões; precisar quais:

Se agruparmos na etiqueta de "Sem opi- nião" aqueles que não responderam ou que não escolheram entre as proposições, notamos as porcentagens abaixo:

\begin{tabular}{c|c|c}
\hline Mal-entendido & Sem opinião & $\begin{array}{c}\text { Interesses } \\
\text { opostos }\end{array}$ \\
\hline $27,3 \%$ & $25,6 \%$ & $47,1 \%$ \\
\hline
\end{tabular}

Podemos estabelecer uma comparação com os resultados obtidos em outros países. Na França, uma pesquisa de Benoît e Maurice mostrou que, numa fábrica parisiense, $57 \%$ dos operários consideravam que as aspirações dos patrões e as dos operários são, em grande parte, totalmente opostas (Benoît; Maurice, 1960, p. 153). Na Noruega, num estudo realizado pelo Instituto de Pesquisas Sociais de Oslo, em 1950-1952, em 12 empresas dessa cidade, a análise da questão "Você pensa que os interesses dos operários e da direção são comuns ou opostos?" revelou os seguintes resultados:

\begin{tabular}{c|c|c}
\hline $\begin{array}{c}\text { Interesses } \\
\text { comuns }\end{array}$ & $\begin{array}{c}\text { Interesses comuns } \\
\text { e opostos }\end{array}$ & $\begin{array}{c}\text { Interesses } \\
\text { opostos }^{6}\end{array}$ \\
\hline $31 \%$ & $31 \%$ & $38 \%$ \\
\hline
\end{tabular}

Essas comparações permitem supor que a industrialização e a urbanização não constituem as únicas variáveis que influem nesse aspecto da consciência de classe. Os partidos políticos, a tradição histórica local do movimento sindical, as condições sociopolíticas e a “cultura política” do país são, provavelmente, fatores cujo papel pode ser decisivo.

Se examinarmos, agora, a relação entre ideologia e a concepção do conflito de classes, observamos uma surpreendente inconsistência na consciência de classe do grupo "radical-ideológico":

\begin{tabular}{c|c|c|c}
\hline Ideologia & $\begin{array}{c}\text { Mal- } \\
\text { entendido }\end{array}$ & $\begin{array}{c}\text { Sem } \\
\text { opinião }\end{array}$ & $\begin{array}{c}\text { Interesses } \\
\text { opostos }\end{array}$ \\
\hline $\begin{array}{c}\text { Comunistas } \\
\text { e socialistas }\end{array}$ & $14,8 \%$ & $7,4 \%$ & $77,8 \%$ \\
\hline Sem filiação & $4,8 \%$ & $52,3 \%$ & $42,9 \%$ \\
\hline Trabalhistas & $35,3 \%$ & $23,5 \%$ & $41,2 \%$ \\
\hline
\end{tabular}

${ }^{6}$ Gulvaag, Harriet. Attitudes and perceptions of representatives and represented in industry, 1953. 
Ainda que o grupo "radical-ideológico", em comparação com os demais, apresente uma consciência muito mais aguda do conflito, uma minoria significativa $(14,8 \%)$ parece assimilar os conflitos sociais como um tipo de "mal-entendido". Tal contradição indica bem o desprendimento existente entre o "tipo ideal" de "consciência radical-ideológica" e sua configuração empírica entre os dirigentes sindicais comunistas e socialistas do Brasil. Essa diferença encontra a sua explicação no papel exercido, durante os últimos trinta anos, pelo principal agente de difusão de ideologias radicais, o Partido Comunista Brasileiro. Esse partido, em geral, e particularmente durante o período de 1954 a 1960 (e mais tarde), dá maior importância aos problemas nacionais do que aos os problemas de classe, destacando a existência de problemas comuns entre a classe operária e a burguesia nacional contra o capital estrangeiro (norte-americano) (Rodrigues, 1966, P. 192; Touraine, 1961, p. 88).

Por fim, tentamos avaliar a relação entre os dois níveis de consciência estudados: a consciência sindical e a consciência radical-ideológica.

\begin{tabular}{l|c|c}
\hline \multicolumn{1}{c|}{ Ideologia } & $\begin{array}{c}\text { Escolha de duas } \\
\text { proposiçóes }\end{array}$ & Unir e organizar \\
\hline $\begin{array}{l}\text { Comunistas e } \\
\text { socialistas }\end{array}$ & $18,5 \%$ & $81,5 \%$ \\
\hline Sem filiação & $23,8 \%$ & $76,2 \%$ \\
\hline Trabalhistas & $32,3 \%$ & $67,7 \%$ \\
\hline
\end{tabular}

Indubitavelmente, observamos uma forte congruência. Porém, mais uma vez, descobrimos a presença de um grupo com opiniões paradoxais: apesar de não atingir a consciência sindical, esse grupo se enquadra na categoria de consciência radical (18,5\%). Podemos apontar duas possíveis explicações que não se excluem: a) a variável significativa, mencionada acima, expressaria a falta de "consciência de conflito" em uma faixa do grupo radical-ideológico, ou seja, a expressão do caráter especificamente "nacionalista" da ideologia difundida pelo Partido Comunista Brasileiro; e (ou) b) ela expressaria o fato de a concepção de sindicato como uma instituição de ajuda social mútua estar fortemente enraizada na classe operária brasileira e aparecer mesmo em alguns de seus dirigentes mais radicais. Isso pode nos conduzir a acreditar que a consciência sindical não é, no Brasil, uma condição prévia ao aparecimento da consciência radical-ideológica.

\section{CONCLUSÕES}

A repartição desse grupo de delegados no Congresso Nacional de Trabalhadores Metalúrgicos em três níveis de consciência de classe revela a preponderância da consciência sindical:

- A consciência radical-ideológica é representada pelo grupo que escolhe os comunistas e os socialistas como os melhores dirigentes sindicais: $32,9 \%$.

- A consciência sindical reúne aqueles que estimam que o objetivo do sindicato é de "unir e de organizar" os trabalhadores na luta pela satisfação de suas reivindicações (menos os comunistas e os socialistas): $47,6 \%$.

- A consciência de identidade de classe é formada por um grupo "residual”, composto de trabalhistas e de operários sem filiação política, que consideram o sindicato como uma instituição de "ajuda mútua social”: 19,5\%.

Não pretendíamos que essas porcentagens refletissem a situação exata da direção sindical metalúrgica no Brasil, em 1959. Nosso objetivo não era tanto determinar a proporção de militantes e de dirigentes sindicais correspondentes a cada nível de consciência de classe, mas tentar mostrar algumas das variáveis significativas capazes de desempenhar um papel na emergência e na estruturação dessa consciência de classe.

O golpe de Estado militar de abril de 1964 teve repercussões consideráveis sobre a estrutura, a orientação e a direção dos sindicatos brasileiros, dentre as quais se destacam: - numerosos dirigentes de esquerda foram presos e (ou) expulsos dos sindicatos e substitu- 
ídos por dirigentes "moderados" (pró-governantes) e (ou) pelos militares;

- uma nova direção sindical local, jovem, clandestina ou semiclandestina, surge inspirada pelas novas tendências ideológicas e mais radicais: cristianismo de esquerda, maoísmo, castrismo, trotskismo, etc.

Esse processo de "radicalização" pode ser uma consequência, por sua vez, do desenvolvimento, em longo prazo, da industrialização, da urbanização e da conjuntura econômica, social e política atual. Sua generalização poderia ter importantes consequências sobre a dinâmica da transformação social no Brasil.

Recebido para publicação em 15 de janeiro de 2018 Aceito em 01 de maio de 2018

\section{REFERÊNCIAS}

BENOÎT, O.; MAURICE, M. Groupes professionnels et relations collectives de travail dans une entreprise. Sociologie du Travail, v. 2, 1960.

CENTERS, R. The Psychology of social classes: a study of class consciousness. Princeton: Princeton University press, 1949.

DOGAN, M. Le vote ouvrier en Europe occidentale. Revue française de sociologie, v. 1, 1960.

GULVAAG, Harriet. Attitudes and perceptions of representatives and represented in industry. Oslo: [S.n.], 1953. v. 2, p. 141.

LÊNIN, V. I. Que faire?Paris: Seuil, 1966.

LOPES, J. R. B. A fixação do operário de origem rural na indústria: um estudo preliminar. Educação e Ciências Sociais, v. 2, n. 6, p. 293-322, nov. 1957.

LUKÁCS, G. Histoire et conscience de classe. Paris: Minuit, 1959.

MARX, K. Die Heilige Familie. Berlin: Dietz Verlag, 1953.

RODRIGUES, L. M. Conflito industrial e sindicalismo no Brasil. São Paulo: Difel, 1966.

SIMÃO, A. O voto operário em São Paulo. In: CONGRESSO BRASILEIRO DE SOCIOLOGIA, 1., 1955, São Paulo. Anais... São Paulo: [S.n.], 1955.

Industrialisation et syndicalisme au Brésil. Sociologie du Travail, v. 1, 1960.

TOURAINE, A. Industrialisation et conscience ouvrière à S. Paulo. Sociologie du Travail, v. 4, 1961. 


\section{STRUCTURE AND WORK CLASS CONSCIOUSNESS IN BRAZIL}

\section{Michael Löwy}

Originally published in French at the Cahier Internatinaux de Sociologie in 1970, the translation of this article, made especially for this dossier, aims to present to the new generations the reflections and research in the field of work sociology of a young student at USP who later became one of the most important authors of the Brazilian social sciences. In this sense, the text has an unparalleled historical value, without losing the current relevance of its problematic. The objective of the article is to elucidate some problems related to the structure of class consciousness of a group of workers present at a 1959 trade union congress. The theoretical reference for this work is Marxism, a perspective that at the time of the research was unaware of the academic milieu.

KEYwORDs:Labor consciousness. Class consciousness. Class identity. Brazilian syndicalism. Marxism.

\section{STRUCTURE DE LA CONSCIENCE DE CLASSE OUVRIERE AU BRESIL}

\author{
Michael Löwy
}

Publié originalement en français, dans le Cahier Internationaux de Sociologie, en 1970, cet article a été traduit spécialement pour ce Dossiêr, avec l'objectif de présenter aux nouvelles générations les réflexions et recherches, dans le domaine de la sociologie du travail, d'une jeune étudiant de l'USP qui deviendra plus tard l'un des autres les plus importants des sciences sociales brésiliennes. En ce sens, le texte a une valeur historique inégalée, sans perdre l'actualité de sa problématique. L'objetif est d'élucider certains problèmes liés à la structure de la conscience de classe d'un groupe de travailleurs présents lors d'un congrès syndical en 1959. La référence théorique pour ce travail est le marxisme.

Mots-clés: Conscience Ouvrière. Conscience de Classe. Sindicalisme brésilien. Marxisme.

Michael Löwy - Sociólogo. Doutor pela Sorbonne, sob a orientação de Lucien Goldmann. Vive em Paris desde 1969, onde trabalha como diretor de pesquisas no CNRS (Centre National de la Recherche Scientifique) e dirigiu um seminário na École des Hautes Études en Sciences Sociales. Considerado um dos maiores pesquisadores das obras de Karl Marx, Leon Trotski, Rosa Luxemburgo, György Lukács, Lucien Goldmann e Walter Benjamin, tornou-se referência teórica para militantes revolucionários de toda a América Latina. Foi homenageado, em 1994, com a medalha de prata do CNRS em Ciências Sociais. É autor de livros e artigos traduzidos em 25 línguas, entre os quais Walter Benjamin: aviso de incêndio (2005), Lucien Goldmann ou a dialética da totalidade (2009), A teoria da revolução no jovem Marx (2012), Para uma sociologia dos intelectuais revolucionários (1979). 
